\title{
Neurogenesis and Differentiation of Sympathetic B and C Cells in the Bullfrog Tadpole
}

\author{
William D. Stofer and John P. Horn \\ Department of Physiology, University of Pittsburgh, School of Medicine, Pittsburgh, Pennsylvania 15261
}

The relation between birthdates of sympathetic neurons and their subsequent differentiation into cutaneous $B$ cells and vasomotor $\mathbf{C}$ cells was examined in paravertebral ganglia 9 and 10 of the bullfrog tadpole. Neurons undergoing terminal cell division were identified by injecting tadpoles repeatedly with 5'-bromodeoxyuridine (BRDU) for one to six developmental stages between III and XXI. After allowing the tadpoles to enter late metamorphic stages (XX-XXV), the ganglia were double immunostained for BRDU and neuropeptide Y (NPY). NPY is a marker for mature C-type neurons (Horn et al., 1987). Double-labeled neurons were readily discerned through use of distinct black and brown HRP reaction products and also because immunoreactivity for BRDU was localized in nuclei while that for NPY was localized in perinuclear cytoplasm. Counts of labeled cells showed that neurogenesis occurs throughout limb bud and paddle stages, and that it ceases during early foot stages (XII-XIV), a time coinciding with the onset of NPY expression. By contrast, the labeling of non-neuronal satellite cells with BRDU was most common weeks later during metamorphic stages. Irrespective of their birthdates, about half of the BRDU-labeled neurons were also positive for NPY immunoreactivity. This proportion of NPY-positive cells is indistinguishable from that in the entire adult ganglia (Horn et al., 1987). In addition to establishing that neurogenesis and gliogenesis occurs during tadpole stages, the results indicate that the onset of NPY expression by vasomotor $C$ neurons is unrelated to their time of origin. In other words, the last wave of neurogenesis in sympathetic ganglia does not give rise to a specific subclass of sympathetic neurons.

[Key words: neurogenesis, neuropeptide Y, B-cell, C-cell, sympathetic ganglia, phenotype, bullfrog, $5^{\prime}$-bromodeoxyuridine]

Sympathetic neurons like most cells of the PNS develop from the neural crest (Le Douarin, 1982; Hall, 1988). Many of the distinctive features that typify functional subsets of mature au-

\footnotetext{
Received May 20, 1992; revised Aug. 11, 1992; accepted Aug. 28, 1992

This study was supported by a grant from the American Heart Association, Pennsylvania Affiliate, and by a Research Career Development Award (KO4 NS01427) from NIH. We thank Dr. Marvin Brown at University of California at San Diego for kindly giving us the rabbit anti-NPY serum. We are most grateful to Ms. Patricia Wohlfarth and Mr. Thomas Waters for their technical assistance to Dr. Gloria Hoffman for advice about color photography, and to Drs. Eric Frank, Cynthia Lance-Jones, and Joe Yip for reading the manuscript.

Correspondence should be addressed to Dr. John P. Horn, Department of Physiology, University of Pittsburgh, School of Medicine, E1440 Biomedical Science Tower, Pittsburgh, PA 15261.

Copyright (C) 1993 Society for Neuroscience $0270-6474 / 93 / 130801-07 \$ 05.00 / 0$
}

tonomic and sensory neurons are thought to be first induced by environmental factors and by specific cellular interactions. These interactions begin during migration of the neural crest and continue after gangliogenesis. For example, when premigratory crest cells are transplanted to a new position along the rostrocaudal axis, they migrate along paths that are appropriate for the new segment (Le Douarin, 1982). Upon forming a ganglion, neural crest cells then differentiate without regard to their segmental origins into cells whose phenotypes are appropriate to their final position (Le Douarin, 1982). The pluripotency of individual ncural crest cells up until their initial migration into somites is supported by clonal analysis (Sieber-Blum and Cohen, 1980; Baroffio et al., 1988; Dupin et al., 1990) and by experiments with lineage tracers (Bronner-Fraser and Fraser, 1989; Fraser and Bronner-Fraser, 1991). At the time when ganglia form, neuronal precursor cells continue to be plastic in some respects, but their properties have begun to diverge. Thus, for example, parasympathetic and sensory neuroblasts withdraw from the cell cycle prior to differentiation, but sympathetic neuroblasts express neuronal markers while still dividing (Rohrer and Thoenen, 1987). In addition, recent retroviral lineage studies of cells from embryonic sympathetic ganglia suggest that neuronal and non-neuronal precursors diverge shortly after gangliogenesis (Hall and Landis, 1991). Based on the expression of cell-specific markers in other experiments, it has been proposed that a common sympathoadrenal lineage gives rise to all subclasses of sympathetic neurons, to ganglionic SIF cells, and to adrenal chromaffin cells (Landis and Patterson, 1981; Anderson and Axel, 1986; Patterson, 1990; Anderson et al., 1991; Carnahan and Patterson, 1991).

Mechanisms that generate diverse subclasses of sympathetic neurons are not fully understood. The best example of this process is the terminal differentiation of cholinergic sympathetic neurons that innervate eccrine sweat glands on foot pads. The conversion of this small subpopulation of neurons from an adrenergic phenotype occurs relatively late in development (Landis and Keefe, 1983; Leblanc and Landis, 1986; Landis et al., 1988). It depends upon specific interactions with the end-organ (Schotzinger and Landis, 1990) and appears to be controlled by a factor released by the target (Rao and Landis, 1990). Comparatively little is known about mechanisms that regulate the expression of different properties by other subclasses that constitute the majority of sympathetic neurons. We have begun to examine this process in paravertebral ganglia of the bullfrog.

Bullfrog sympathetic neurons in the lumbar paravertebral ganglia are organized into well-characterized $\mathrm{B}$ and $\mathrm{C}$ phenotypes (Nishi et al., 1965; Dodd and Horn, 1983). These subclasses all synthesize epinephrine as their primary transmitter (von Euler, 1971). B and C neurons are defined and distin- 
guished by their electrophysiological properties, their synaptic connections, and their functional modalities. Important elements of this basic functional organization appear to be conserved in higher vertebrates including man (Janig and Szulczyk, 1981; Janig et al., 1983). In the bullfrog, sympathetic fast and slow B neurons project selectively to nonvascular cutaneous targets that probably include mucous and toxin glands (Horn et al., 1988). C cells are vasoconstrictor neurons that control blood flow in the skin and in skeletal muscle (Stofer et al., 1990). C neurons, which constitute $\sim 55 \%$ of the total, are further distinguished by their selective expression of neuropeptide Y (NPY) (Horn et al., 1987). In addition to its putative function as a cotransmitter, NPY therefore serves as an accurate anatomical marker for distinguishing $\mathrm{C}$ cells from $\mathrm{B}$ cells.

During development, the onset of NPY expression begins in tadpoles at stage XI (Stofer and Horn, 1990). The proportion of NPY-positive neurons increases monotonically for about 2 months and reaches a plateau, at adult levels, by stage $\mathrm{XX}$. Since dividing neurons were not found in these earlier experiments, the observations of NPY were interpreted as evidence for the gradual maturation of postmitotic sympathetic $\mathrm{C}$ neurons. However, an alternative explanation is suggested by two recent findings in the bullfrog. First, the number of sympathetic neurons continues to increase in developing young frogs (Farel and Baek, 1989; St. Wecker and Farel, 1991). This suggests that either mitotic activity or cell migration continues throughout development. Second, the birth of sensory neurons in brachial dorsal root ganglia spans many of the early tadpoles stages (Mendelson and Frank, 1990). This implies that their sympathetic brethren may observe similar behavior. Together, both sets of findings suggest that the onset of NPY expression could reflect a late wave of histogenesis in which $\mathrm{C}$ cells are preferentially added to sympathetic ganglia. The present experiments were designed to test this possibility. In order to determine the birthdates of cells, we have injected tadpoles at various stages of development with 5 -bromodeoxyuridine (BRDU). BRDU is a thymidine analog that is incorporated into the DNA of dividing cells. It remains undiluted in cells undergoing terminal mitosis at the time of exposure, and can later be detected with a monoclonal antibody (Gratzner, 1982). After waiting for the tadpoles to mature beyond stages associated with the plateau of NPY expression, the sympathetic ganglia were double immunostained for NPY and BRDU. We predicted that if the onset of NPY expression is caused by a late wave of $C$ cell histogenesis, then a high proportion (i.e., $>55 \%$ ) of late-born neurons would express NPY.

\section{Materials and Methods}

Animals. The 45 tadpoles (Rana catesbiana) used in the present experiments were obtained from Charles D. Sullivan Co. (Nashville, TN). They were staged by the criteria of Taylor and Kollros (1946) and maintained in aquaria (Stofer and Horn, 1990).

$B R D U$ injections. Tadpoles were anesthetized by immersion in ice water for $10 \mathrm{~min}$ prior to each injection. After nine preliminary experiments to establish an optimal regimen, all of the tadpoles that were uscd for cell counting reccived scven injections containing $1 \mathrm{mg}$ of BRDU (Boehringer) in $0.1 \mathrm{ml}$ of Ringer's over $15 \mathrm{~d}$. The injections were made deep into the rostral tail musculature and were administered on days $1,3,6,8,11,13$, and 15 . Tadpoles were then allowed to mature until stages XX-XXV before preparation for histology.

Preparation of tissue. The procedures for perfusion of tadpoles with fixative containing $4 \%$ paraformaldehyde, for blocking and embedding of torsos containing sympathetic ganglia 9 and 10 , and for cutting and mounting of frozen $10 \mu \mathrm{m}$ sections have all been described elsewhere (Stofer and Horn, 1990). Blocks of tissue containing the dorsal body wall and the paravertebral chain ganglia were serially sectioned in the frontal plane, transverse to the neuraxis. Ganglia 9 and 10 were contained in about 250 sections per animal.

Immunocytochemistry. Sections containing ganglia 9 and 10 were double-stained for NPY immunoreactivity (NPY-IR) and BRDU immunoreactivity (BRDU-IR) using sequential two-color horseradish peroxidase (HRP) immunocytochemistry, and then lightly counterstained with thionin. The double-labeling procedure was modified from the method of Soriano and Del Rio (1991).

Sections on slides were processed first for NPY-IR. They were initially rinsed in $0.1 \mathrm{M}$ PBS (pH 7.4) and then in 3\% goat serum in PBS $(20$ $\mathrm{min}$ ). They were subsequently incubated in primary antiserum overnight at $4^{\circ} \mathrm{C}$ in Coplin jars. The rabbit anti-NPY serum (gift of Dr. Marvin Brown, Univeristy of California at San Diego) was diluted with PBS (1: $20,000), 1 \%$ goat serum, and $0.1 \%$ Triton $X-100$. The slides were washed three times in PBS, and areas surrounding the sections were wiped dry with tissue paper. Drying the slides in this fashion left a low-volume droplet of liquid over the tissue. The droplet of PBS was then quickly removed and carefully replaced with $80 \mu \mathrm{l}$ of goat anti-rabbit serum coupled to HRP (TAGO). The secondary antiserum was diluted with PBS $(1: 400)$ and $1 \%$ goat serum. Sections were incubated in secondary antiserum in a moist chamber for $2 \mathrm{hr}$ at room temperature. HRP histochemistry to produce a brown reaction product began with three $5 \mathrm{~min}$ rinses in PBS, which were followed by $10 \mathrm{~min}$ preincubation in $0.05 \%$ diaminobenzidine (DAB), and $5 \mathrm{~min}$ incubation in $0.05 \% \mathrm{DAB}$ and $0.01 \% \mathrm{H}_{2} \mathrm{O}$. The reaction was stopped with three $5 \mathrm{~min}$ rinses in PBS.

Sections were processed second for BRDU-IR. In order to denature DNA so that it could bind the BRDU antibody, the slides were first placed in Coplin jars and given two $15 \mathrm{~min}$ washes in $2 N \mathrm{HCl}$ in PBS with $0.5 \%$ Triton. After a 20 min wash with $3 \%$ goat serum in PBS, each slide was incubated in a low volume $(80 \mu \mathrm{l})$ of mouse anti-BRDU (Boehringer) diluted in PBS (1:20), 1\% goat serum, and $0.1 \%$ Triton. The slides were coverslipped and then incubated overnight in a moist chamber at $4^{\circ} \mathrm{C}$. The next day, coverslips were removed by soaking the slides in PBS. Following three additional rinses in PBS, HRP-coupled goat anti-mouse serum (Cappel) diluted in PBS (1:50), and 1\% goat serum was applied to each slide in a low volume. The slides were incubated in secondary antibody for $2 \mathrm{hr}$ in a moist chamber at room temperature and then processed with a nickel-enhanced $\mathrm{DAB}$ reaction that yields a black product. This involved three $5 \mathrm{~min}$ rinses in $0.1 \mathrm{M}$ Tris Buffer (pH 7.6), 10 min preincubation in $0.2 \% \mathrm{NiNH}_{4} \mathrm{SO}_{4}$ in Tris buffer, 10 min preincubation in $0.05 \% \mathrm{DAB}$ and $0.2 \% \mathrm{NiNH}_{4} \mathrm{SO}_{4}$ in Tris buffer, and $10 \mathrm{~min}$ incubation in $0.05 \% \mathrm{DAB}, 0.2 \% \mathrm{NiNH}_{4} \mathrm{SO}_{4}$, and $0.01 \% \mathrm{H}_{2} \mathrm{O}_{2}$ in Tris buffer. The reaction was stopped by washing in PBS.

After immunostaining, all sections were counterstained with thionin, dehydrated in graded alcohols, defatted in xylene, and coverslipped with Permount.

Cell counts. In 10 animals (animals $\mathrm{A}-\mathrm{I}$ and $\mathrm{K}$ in Table 1), every fourth section (range, 48-64 sections) was examined at $400 \times$ for the presence of labcled principal ganglionic ncurons in both sympathetic chains. Analysis of nonadjacent sections in this manner eliminates double counting of split cells. Based on comparison with systematic counts of serial sections, this method provides an accurate estimate of the proportion of NPY-positive neurons in ganglia 9 and 10 (Horn and Stofer, 1988; Stofer and Horn, 1990). In four animals that received late injections of BRDU (J, L, M, and N in Table 1) only one-eighth of the sections on half of the slides were analyzed because no labeled cells were found in the initial 21-24 sections that were examined.

The reliability of counts from different animals was compared by estimating the associated counting errors. For this purpose it was assumed that the processes of cell birth and initial NPY expression follow Poisson distributions. This assumption implies that the rates of cell birth and differentiation are low and that the processes are random. The former assumption is supported by the low rate of cell division obtained in the results and the latter is supported by the pluripotency of the neural crest. The standard deviation of a count is therefore equal to the square root of the count, and the coefficient of variation (CV) is equal to the standard deviation divided by the count (Colquhoun, 1971). Counting errors in the percentage of double-labeled neurons were calculated by combining CV values according to the equation $\mathrm{CV}(x / y)=[\mathrm{CV}(x)+$ $\mathrm{CV}(y)]^{0.5}$. 


\begin{tabular}{|c|c|c|c|c|c|c|}
\hline Animal & $\begin{array}{l}\text { First } \\
\text { injection }\end{array}$ & $\begin{array}{l}\text { Last } \\
\text { injection }\end{array}$ & $\begin{array}{l}\text { End } \\
\text { stage }\end{array}$ & $\begin{array}{l}\text { BRDU- } \\
\text { positive } \\
\text { cells }\end{array}$ & $\begin{array}{l}\text { NPY and } \\
\text { BRDU } \\
\text { double- } \\
\text { positive } \\
\text { cells }\end{array}$ & $\begin{array}{l}\% \text { Cells } \\
\text { doubled labeled }\end{array}$ \\
\hline A & III & IV & XXV & 91 & 31 & 34 \\
\hline B & IV & $\mathrm{V}$ & XXV & 163 & 95 & 58 \\
\hline $\mathrm{C}$ & IV & VII & XXV & 211 & 102 & 48 \\
\hline $\mathrm{D}$ & $\mathrm{X}$ & XIV & XXV & 97 & 49 & 51 \\
\hline $\mathrm{E}$ & $\mathrm{X}$ & XIV & XXV & 37 & 21 & 57 \\
\hline F & $\mathrm{X}$ & XIV & XXV & 29 & 12 & 41 \\
\hline G & $\mathrm{X}$ & XIV & XXV & 32 & 16 & 50 \\
\hline $\mathrm{H}$ & XII & XVII & XXV & 8 & 4 & 50 \\
\hline I & XII & XVIII & XXIII & 0 & 0 & - \\
\hline $\mathbf{J}$ & XII & XVIII & XXII & 0 & 0 & - \\
\hline K & XIV & XVIII & XXIII & 4 & 3 & 75 \\
\hline $\mathrm{L}$ & XIV & XVIII & XX & 0 & 0 & - \\
\hline $\mathbf{M}$ & XVII & $\mathrm{XX}$ & $\mathrm{XX}$ & 0 & 0 & - \\
\hline $\mathrm{N}$ & XVIII & XXI & XXI & 0 & 0 & - \\
\hline Total & & & & 672 & 333 & $52 \pm 12( \pm \mathrm{SD})$ \\
\hline
\end{tabular}

\section{Results}

The development of bullfrog tadpoles takes 3-6 months under the controlled laboratory conditions that were employed. This presents a problem in performing a birthdating analysis because it suggests that at any instant only a very small number of neuroblasts may be dividing, even during active times in development. Indeed, initial attempts to label tadpoles with single injections of BRDU proved futile. Preliminary experiments were therefore performed to establish the optimal dose and regimen for administering BRDU. Since the cryostat sections used in these experiments include the entire dorsal body wall, it was possible to examine BRDU incorporation not only into sympathetic neurons but also into skin, muscle, cartilage, and the spinal cord. At lower doses of BRDU (10-100 $\mu \mathrm{g})$, labeled cell nuclei were seen only in more mitotically active tissues like skin. At higher doses ( $>1 \mathrm{mg}$ ), the tadpoles ceased to develop, their
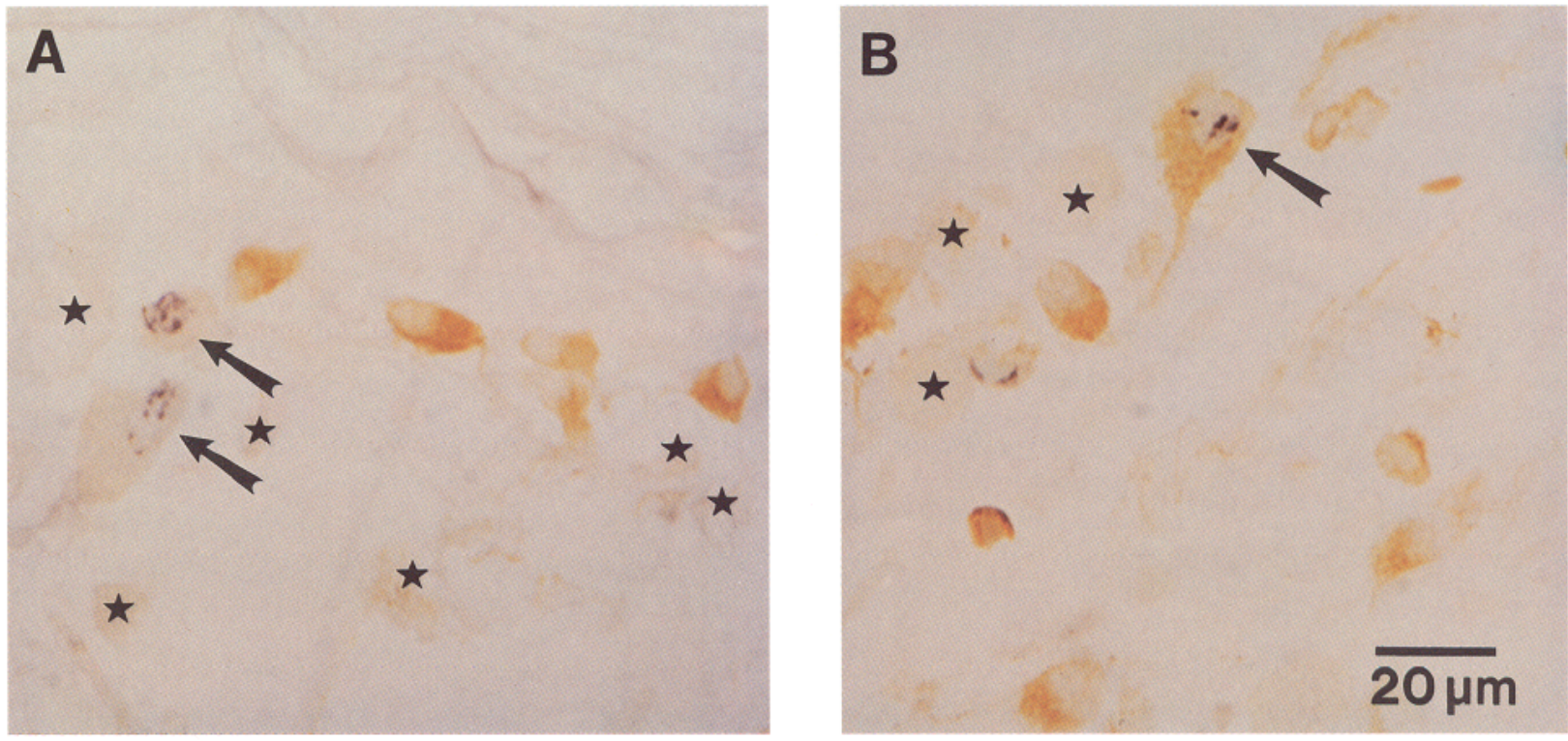

Figure 1. Double-immunostaining of sympathetic neurons for BRDU and NPY. The four possible combinations of double labeling are illustrated. $A$ contains examples of two neurons with black nuclear staining for BRDU (arrows), of neurons with brown cytoplasmic staining for NPY, and of pale unlabeled neurons (stars). It comes from a frog that received BRDU injections between stages III and IV (animal A). $B$ contains a neuron that is double labeled (arrow). Other neurons in this field are either unlabeled (stars) or single labeled for NPY. $B$ comes from a frog that received BRDU injections between stages IV and VII (animal C). 


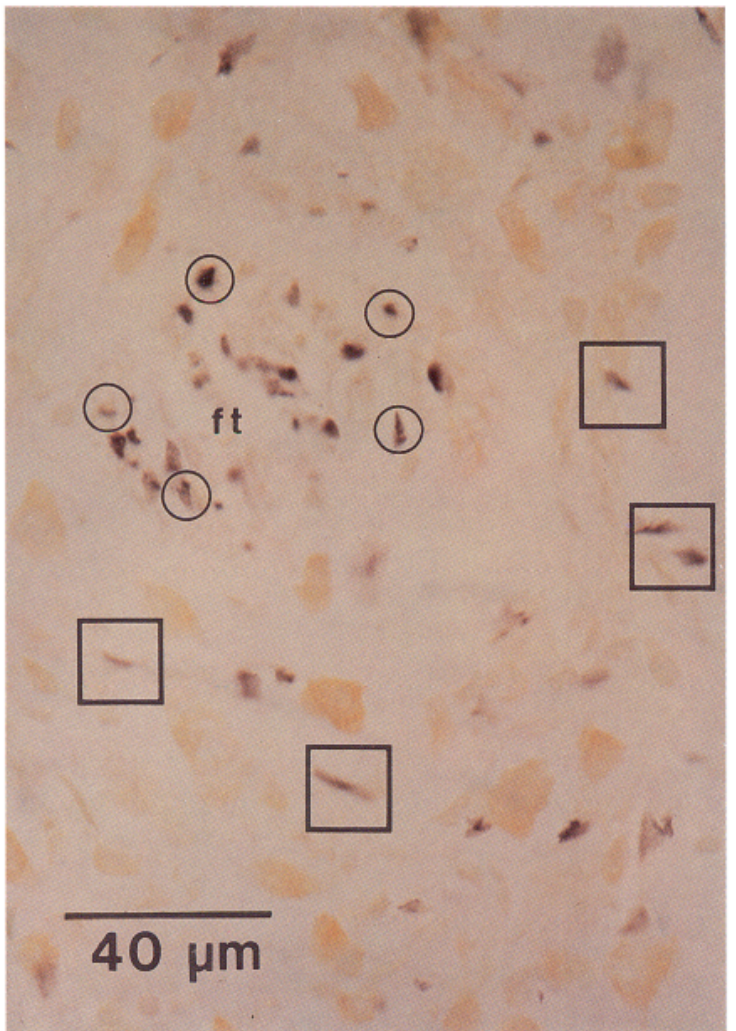

Figure 2. BRDU-IR (black) in small non-neuronal cells is most prevalent in animals labeled during metamorphic stages. This example comes from animal M, which received BRDU injections between stages XVII and XX. Many of the labeled non-neuronal cells were in close apposition to neurons and are therefore presumed to be Schwann cells. In this representative section, the highest number of labeled cells is in an axonal fiber tract $(f t)$ running through the center of the ganglion. Several BRDUlabeled cells at the perimeter of the fiber tract are marked with circles. In addition, there are small labeled cells adjacent to neuronal cell bodies. Several examples of these labeled cells that are scattered throughout the entire ganglion are marked with squares.

tails often appeared crinkled, and many died. The data presented below come from 14 animals labeled with seven $1 \mathrm{mg}$ doses over 2 weeks. This protocol labeled neurons in the spinal cord and in sensory and sympathetic ganglia. It yielded maximal labeling of sympathetic neurons in paravertebral ganglia 9 and 10 , and minimized the developmental arrest and morbidity seen with higher doses or longer injection schedules.

As expected, BRDU-IR and NPY-IR differed in their cellular localization (Fig. 1). In sympathetic neurons, BRDU-IR characteristically appeared as clumps of black HRP reaction product within the nucleus. BRDU-IR was also present in some of the glia that ensheath neuronal cell bodies and axons (Fig. 2), in non-neuronal cells that comprise the connective tissue capsule surrounding the ganglia, and in some cell fragments that were too small to identify. The BRDU-IR in satellite cells was generally more diffuse and granular than that in neurons. In contrast to the appearance of BRDU-IR, the reaction product for NPYIR was brown, granular, and localized in the perinuclear cytoplasm of sympathetic neurons. NPY-IR was also present in some axons. Neurons that were immunoreactive for both BRDU and NPY could easily be discerned due to the differences in color and location of the two reaction products. Figure 1 shows that all of the four possible combinations of unlabeled, single- labeled, and double-labeled neurons were present in sympathetic ganglia.

The time course of neurogenesis was evaluated from systematic counts of neurons in 14 tadpoles that had been treated with BRDU (Table 1). Cell fragments with BRDU-IR were excluded from the counts if they could not be identified unambiguously as neurons. Every BRDU-positive neuron was also scored for the presence of NPY. The largest numbers of BRDU-positive neurons were found in animals that received their last injection prior to stage VII. Specifically, in three animals (animals A-C) that received initial BRDU injections between stages III and IV, an average of $155 \pm 60( \pm S D)$ neurons were labeled. The extent of BRDU labeling was much lower at later stages. Only $49 \pm 32$ neurons were labeled in the four animals (D-G) receiving initial BRDU injections between stages $\mathrm{X}$ and XIV. In seven animals $(\mathrm{H}-\mathrm{N})$ that were injected at stage XII or later, a combined total of only 12 labeled neurons were found.

The raw counts of BRDU-positive neurons could have been biased, in principle, by the fact that each animal generated a different number of sections. In order to test this possibility, the data were normalized to express numbers of BRDU-positive neurons per section that was counted. When the resulting mitotic index was plotted against the period of BRDU exposure (Fig. 3 ), it revealed the same trends as observed in the raw counts. The incidence of sympathetic neurons undergoing terminal mitosis in tadpoles is highest during the limb bud stages (I-V), declines during the paddle stages (VI-X), and ceases during the foot stages (XI-XVII). In order to compare the time course of neurogenesis with the onset of NPY, data describing the latter are reproduced (Stofer and Horn, 1990) in Figure 3. The comparison suggests little, if any, temporal overlap between these developmental events.

Is there a relation between the birthdate and phenotypic fate of sympathetic neurons? There were double-positive neurons containing BRDU-IR and NPY-IR in all nine tadpoles that were successfully labeled with BRDU (Table 1). Summing all the counts, $50 \%$ (333 of 672) of the BRDU-positive neurons were also NPY positive. On a case-by-case basis, the percentage of double-positive neurons ranged between $34 \%$ and $75 \%$, with a mean of $52 \pm 12 \%( \pm \mathrm{SD})$. A plot of birthdate against the percentage of NPY-positive neurons (Fig. 4) shows that there is no correlation between the time of origin of sympathetic neurons and their expression of NPY $(R=0.51)$.

Although no attempt was made to quantitate the birthdates of non-neuronal satellite cells (Fig. 2), they were very different from those of neurons. Unlike the case of neurons where mitosis peaks during early (i.e., limb bud) stages, BRDU-IR in nonneuronal cells was most prevalent in sympathetic ganglia from animals that had been injected during the foot and metamorphic stages. During this period, mitotic activity was especially obvious in fiber tracts within the ganglia (Fig. 2) and in interganglionic regions of the sympathetic chain. The specificity of this labeling for the sympathetic chain was supported by the complete absence of BRDU-IR in smooth muscle and connective tissue of the adjacent aorta (not shown).

\section{Discussion}

Previous workers have examined the development of many neural crest derivatives (e.g., Landis and Patterson, 1981; Le Douarin, 1982; Hall, 1988; Patterson, 1990), but relatively little is known about the origins of those sympathetic neurons that se- 


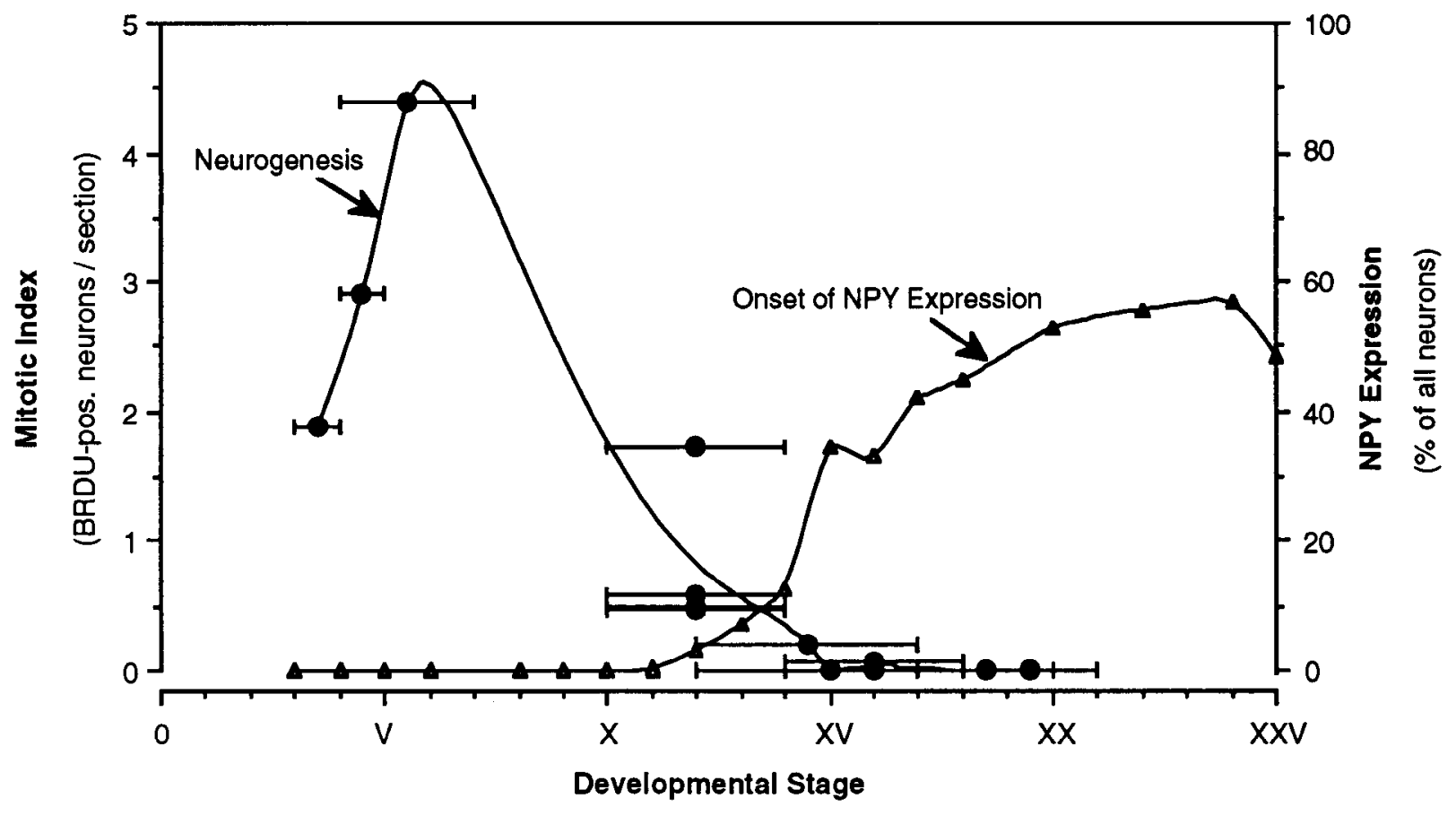

Figure 3. The developmental time course of neurogenesis (circles) and the onset of NPY expression (triangles) in sympathetic ganglia. Each point represents one tadpole. Mitotic indices are plotted at the midpoint of exposure to BRDU. Error bars indicate the entire period of BRDU exposure and thus the birthdate. Data illustrating the onset of NPY expression are replotted from Stofer and Horn (1990). A comparison of these two events shows that they follow different time courses.

lectively innervate blood vessels. In this study we exploited the fact that, in the mature bullfrog, NPY is a faithful anatomical marker for vasomotor sympathetic neurons, also known as $\mathrm{C}$ cells (Horn et al., 1987; Horn and Stofer, 1988; Stofer et al., 1990). The results provide the first direct evidence of mitotic activity in sympathetic ganglia of the bullfrog tadpole and demonstrate how the BRDU incorporation method can be used to study histogenesis in this system. Neurogenesis was maximal between stages III and VII and ceased prior to metamorphosis. By contrast, the labeling of presumptive glial cells with BRDU was most evident in metamorphic animals. There was no correlation between the time of origin of sympathetic neurons and their subsequent expression of NPY. Moreover, there was little temporal overlap between the period of neurogenesis and the onset of NPY expression as defined in an earlier study (Stofer and Horn, 1990). Thus, the onset of NPY expression must reflect the differentiation of postmitotic vasomotor $\mathrm{C}$ neurons and not the selective addition of newborn $C$ cells to the ganglia. It appears that neuronal birthdates do not determine the fates of vasomotor C cells or cutaneous B cells this system.

In order to evaluate the present results, it is important to know whether BRDU accurately labels the pool of neurons that are leaving the mitotic cycle. BRDU is highly toxic in addition to acting as a thymidine analog that is incorporated into DNA during cell division. By adjusting the dosage of BRDU, it has been used experimentally as a mutagen, teratogen, carcinogen, and inhibitor of cell differentiation (Goz, 1978). In developmental studies, BRDU has often been applied in single-pulse, tracer level doses (Wynford-Thomas and Williams, 1986; Boswald et al., 1990). However, we found in preliminary experiments that single injections of BRDU were inadequate for labeling bullfrog sympathetic neurons. This may simply reflect the low rate of neurogenesis in this system. The larval stages of development in bullfrogs take at least 12-36 weeks, and at the end of metamorphosis the lumbar ganglia contain only about 3400 sympathetic neurons (St. Wecker and Farel, 1991). In order to label more neurons, we therefore used multiple injections at relatively high doses. Higher dosages are thought to make BRDU available for longer periods of time (Boswald et al., 1990).

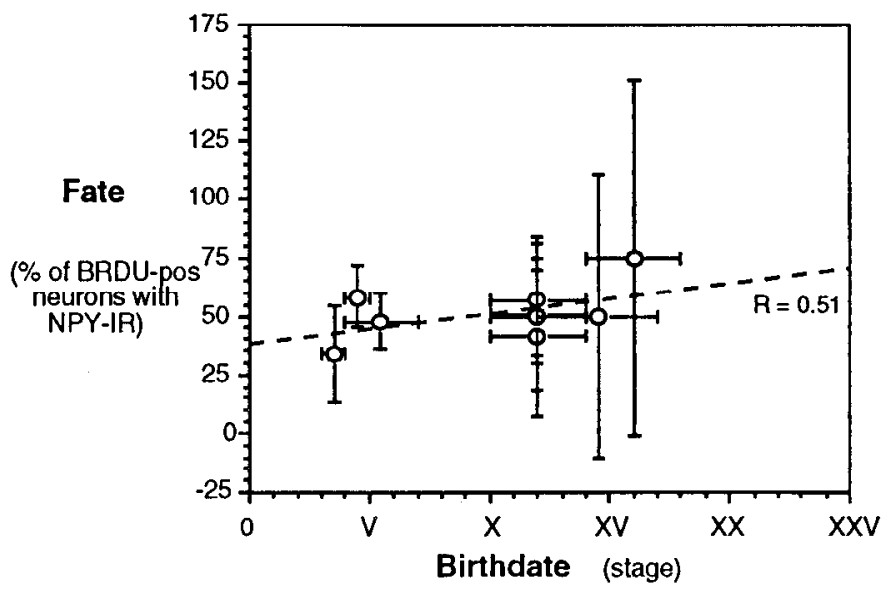

Figure 4. The birthdates and fates of sympathetic neurons are not correlated. The percentage of neurons expressing NPY reflects the proportion of $\mathrm{C}$ neurons in the ganglia. The alternative fate of not expressing NPY is indicative of the B cell phenotype. Each point represents one tadpole. Error bars on the $x$-axis denote the period of BRDU exposure. Error bars on the $y$-axis denote the counting errors (see Materials and Methods). The counting errors were very large for the two animals at later stages because very few neurons (i.e., eight and four) were labeled in these cases. The broken line is a linear regression fit to the data. 
Were the doses used in our study sufficient to label all dividing cells? The definitive answer to this question can only be provided by accounting for the births of all neurons in the ganglia. Unfortunately, our data are not sufficient for this purpose. Nonetheless, there are two indirect arguments that BRDU labeling accurately charts the period of histogenesis in the lumbar sympathetic ganglia. First of all, BRDU did not alter the normal pattern of NPY expression. Although we did not undertake systematic counts, it was clear that the overall proportion of sympathetic neurons expressing NPY-IR after injection of BRDU resembled the normal value of 50-55\% (Horn et al., 1987; Stofer and Horn, 1990). Second, the numbers of neurons labeled with BRDU were substantial and comparable to other results using tritiated thymidine as a tracer. Knowing that the lumbar ganglia contain 3400 sympathetic neurons at the end of metamorphosis (St. Wecker and Farel, 1991), one can estimate the proportion of neurons labeled with BRDU. Counts in Table 1 were divided by 2 to produce a unilateral count and multiplied by 4 to compensate for counting every fourth section. In this manner, it is estimated that BRDU labeled $\sim 5 \%$ of all neurons between stages III and IV (animal A), 12\% between stages IV and VII (C), and $\sim 3 \%$ between stages X and XIV (D-G). Summing the numbers, the data show that at least $21 \%$ of the sympathetic neurons in the lumbar ganglia are born between stages III and XIV.

The birth of a substantial fraction of sympathetic neurons during tadpole stages is similar to recent evidence about the ontogeny of sensory neurons in the tadpole (Mendelson and Frank, 1990). Using tritiated thymidine rather than BRDU, Mendelson and Frank (1990) also found it necessary to employ repeated injections in order to label substantial numbers of sensory neurons. They estimated that $\sim 50 \%$ of sensory neurons in a dorsal root ganglion were born at stages $\mathrm{V}$ or later, and that neurogenesis ended by stage XV. Although different labels and different dosage protocols werc cmployed in these two studies, the results imply that roughly similar proportions of the sensory and sympathetic neuronal populations are generated during the same stages of tadpole development.

Evidence for the birth of sympathetic (present results) and sensory (Mendelson and Frank, 1990) neurons in the bullfrog tadpole is interesting in view of reports that their numbers both increase after metamorphosis (Farel and Baek, 1989; St. Wecker and Farel, 1989, 1991). It suggests that the new neurons arise through differentiation of small postmitotic cells within the ganglia or possibly through migration of postmitotic neurons into the ganglia.

The present results clearly illustrate the temporal relationships between birthdates of sympathetic neurons and the acquisition of transmitter phenotypes. The simple finding that neurons leave the cell cycle during tadpole stages demonstrates an important parallcl with the sympathetic lineage in birds and mammals. Given that all cells in bullfrog sympathetic ganglia express immunoreactivity for tyrosine hydroxylase by stage III (Stofer and Horn, 1990), it is now clear that amphibian neuroblasts begin to differentiate prior to withdrawal from the cell cycle. This principle is already well-established in higher vertebrates (Rothman et al., 1978; Rohrer and Thoenen, 1987; DiCicco-Bloom and Black, 1988). By contrast, there appears to be a different temporal relation between neuronal birth and NPY expression. Since much fewer than half (i.e., 3\%) of sympathetic neurons are born after the onset of NPY expression, it appears most likely that they begin expressing NPY after leaving the cell cycle.
The relation between these events is less clear and more difficult to study in mammalian sympathetic ganglia because of the larger overlap between the period of neurogenesis and the onset of NPY expression (Hendry, 1977; Hall and Landis, 1991; Tyrrell et al., 1991).

In a recent study of murine enteric neurons, Pham et al. (1991) looked at the birthdates of myenteric and submucosal neurons that express peptidergic (including NPY) and nonpeptidergic (5-HT, ACh) phenotypes. They found evidence for temporal segregation between the early origin of nonpeptidergic neurons and the later appearance of peptidergic neurons. This suggests that the sequential timing of environmental cues may determine, in some cases, the properties of autonomic neurons. This may prove relevant to our results because of recent evidence that enteric and sympathetic neurons arise from a common sympathoadrenal lineage (Carnahan et al., 1991).

One obvious difference in birthdates within tadpole sympathetic ganglia is that between neurons and glia. BRDU incorporation ended in neurons before glia. This finding is consistent with recent evidence in the rat superior cervical sympathetic ganglion where Hall and Landis (1991) used retroviral marking to follow cell clones in cultures of embryonic ganglia. They found that clones giving rise to neurons disappeared at earlier stages than those producing glia. This was interpreted as evidence of divergence between two lineages. Although other interpretations are possible, our findings have similar implications.

To summarize, the results of this study show a lack of correlation between neuronal birthdates and NPY expression. They also demonstrate that individual $C$ neurons withdraw from the cell cycle prior to expressing NPY, and that gliogenesis persists after neurogenesis. However, the results do not indicate that neurogenesis precedes the initial commitment to the $\mathrm{B}$ and $\mathrm{C}$ phenotypes. Are the fates of $B$ and $C$ neurons determined prior or subsequent to their leaving the mitotic cycle? Using other criteria, namely, axonal conduction velocities and segmental innervation patterns, $\mathrm{B}$ and $\mathrm{C}$ cells can be distinguished as early as stage III (Horn, 1990). This means that B and C cells begin to differentiate long before many sympathetic neurons are born. Because of the overlap between these events, one cannot infer their temporal order at the single-cell level. A similar problem exists in the rat superior cervical ganglion, where the onsets of neurogenesis and synaptogenesis are virtually simultaneous (Hendry, 1977; Rubin, 1985; Hall and Landis, 1991). It remains to be learned when and how the phenotypic fates of different adrenergic sympathetic neurons are specified and the relation of this process to selective synapse formation in the ganglia. These events may now prove to be experimentally accessible in the bullfrog tadpole.

\section{References}

Anderson DJ, Axel R (1986) A bipotential neuroendocrine precursor whose choice of cell fate is determined by NGF and glucocorticoids. Cell 47:1079-1090.

Anderson DJ, Carnahan JF, Michelsohn A, Patterson PH (1991) Antibody markers identify a common progenitor to sympathetic neurons and chromaffin cells in vivo and reveal the timing of commitment to neuronal differentiation in the sympathoadrenal lineage. J Neurosci 11:3507-3519.

Baroffio A, Dupin E, Le Douarin N (1988) Clonc-forming ability and differentiation of migratory neural crest cells. Proc Natl Acad Sci USA 85:5325-5329.

Boswald M, Harasim S, Maurer-Schultze B (1990) Tracer dose and availability of thymidine and bromodeoxyuridine: application of bromodeoxyuridine in cell kinetic studies. Cell Tissue Kinet 23:169-181. 
Bronner-Fraser M, Fraser S (1989) Developmental potential of avian trunk neural crest cells in situ. Neuron 3:755-766.

Carnahan JF, Patterson PH (1991) Isolation of the progenitor cells of the sympathoadrenal lineage from embryonic sympathetic ganglia with the SA monoclonal antibodies. J Neurosci 11:3520-3530.

Carnahan IF, Anderson DJ, Patterson PH (1991) Evidence that enteric neurons may derive from the sympathoadrenal lineage. Dev Biol 148: $552-561$.

Colquhoun D (1971) Lectures on biostatistics. Oxford: Clarendon.

DiCicco-Bloom E, Black IB (1988) Insulin growth factors regulate the mitotic cycle in cultured rat sympathetic neuroblasts. Proc Natl Acad Sci USA 85:4066-4070.

Dodd J, Horn JP (1983) A reclassification of B and C neurones in the ninth and tenth paravertebral sympathetic ganglia of the bullfrog. J Physiol (Lond) 334:255-269.

Dupin E, Baroffio A, Dulac C, Cameron-Curry P, Le Dourin NM (1990) Schwann-cell differentiation in clonal cultures of the neural crest, as evidenced by the anti-Schwann cell myelin protein monoclonal antibody. Proc Natl Acad Sci USA 87:1119-1123.

Farel PB, Baek JK (1989) Neuron number increases in postmetamorphic bullfrogs: sympathetic ganglia. Soc Neurosci Abstr 15:301.

Fraser SE, Bronner-Fraser M (1991) Migrating neural crest cells in the trunk of the avian embryo are multipotent. Development 112:913920.

Goz B (1978) The effects of incorporation of 5-halogenated deoxyuridines into DNA of eukaryotic cells. Pharmacol Rev 29:249-272.

Gratzner HG (1982) Monoclonal antibody to 5-bromo and 5-iododeoxyuridine: a new reagent for detection of DNA replication. Science 218:474-475.

Hall AK, Landis SC (1991) Early commitment of precursor cells from the rat superior cervical ganglion to neuronal or nonneuronal fates. Neuron 6:741-752.

Hall BK (1988) The neural crest. New York: Oxford UP.

Hendry IA (1977) Cell division in the developing sympathetic nervous system. J Neurocytol 6:299-309.

Horn JP (1990) Development of fast synaptic transmission in bullfrog sympathetic ganglia. J Auton Nery Syst 32:107-120.

Horn JP, Stofer WD (1988) Double labeling of the paravertebral sympathetic C system in the bullfrog with antisera to LHRH and NPY. J Auton Nerv Syst 23:17-24.

Horn JP, Stofer WD, Fatherazi S (1987) Neuropeptide Y-like immunoreactivity in bullfrog sympathetic ganglia is restricted to $\mathrm{C}$ cells. J Neurosci 7:1717-1727.

Horn JP, Fatherazi S, Stofer WD (1988) Differential projections of B and $\mathrm{C}$ sympathetic axons in peripheral nerves of the bullfrog. J Comp Neurol 278:570-580.

Janig W, Szulczyk P (1981) The organization of lumbar preganglionic neurons. J Auton Nerv Syst 3:177-191.

Janig W, Sundlof G, Wallin BG (1983) Discharge patterns of sympathetic neurons supplying skeletal muscle and skin in man and cat. J Auton Nerv Syst 7:239-256.

Landis SC, Keefe D (1983) Evidence for neurotransmitter plasticity in vivo: developmental changes in properties of cholinergic sympathetic neurons. Dev Biol 98:349-372.

Landis SC, Patterson PH (1981) Neural crest cell lineages. Trends Neurosci 4:172-175.

Landis SC, Siegel RE, Schwab M (1988) Evidence for neurotransmitter plasticity in vivo. II. Immunocytochemical studies of rat sweat gland innervation during development. Dev Biol 126:129-140.
Leblanc G, Landis S (1986) Development of choline acetyltransferase (CAT) in the sympathetic innervation of rat sweat glands. J Neurosci $6: 260-265$

Le Douarin NM (1982) The neural crest. New York: Cambridge UP.

Mendelson B, Frank E (1990) Times of origin of brachial sensory neurons are not correlated with neuronal phenotype. J Comp Neurol 300:422-432

Nishi S, Soeda H, Koketsu K (1965) Studies on sympathetic B and C neurons and patterns of preganglionic innervation. J Cell Comp Physiol 66:19-32.

Patterson PH (1990) Control of cell fate in a vertebrate neurogenic lineage. Cell 62:1035-1038.

Pham TD, Gershon MD, Rothman TP (1991) Time of origin of neurons in the murine enteric nervous system: sequence in relation to phenotype. J Comp Neurol 314:789-798.

Rao MS, Landis SC (1990) Characterization of a target-derived neuronal cholinergic differentiation factor. Neuron 5:899-910.

Rohrer H, Thoenen H (1987) Relationship between differentiation and terminal mitosis: chick sensory and ciliary neurons differentiate after terminal mitosis of precursor cells, whereas sympathetic neurons continue to divide after differentiation. J Neurosci 7:3739-3748.

Rothman TB, Gershon MD, Holtzer H (1978) The relationship of cell division to the acquisition of adrenergic characteristics by developing sympathetic ganglion cell precursors. Dev Biol 65:322-341.

Rubin E (1985) Development of the rat superior cervical ganglion: initial stages of synapse formation. J Neurosci 5:697-704.

Schotzinger RJ, Landis SC (1990) Acquisition of cholinergic and peptidergic properties by sympathetic innervation of rat sweat glands requires interaction with normal target. Neuron 5:91-100.

Sieber-Blum M, Cohen AM (1980) Clonal analysis of quail neural crest cells: they are pluripotent and differentiate in vitro in the absence of noncrest cells. Dev Biol 80:96-106.

Soriano E, Del Rio JA (1991) Simultaneous immunocytochemical visualization of bromodeoxyuridine and neural tissue antigens. J Histochem Cytochem 39:255-263.

Stofer WD, Horn JP (1990) Expression of neuropeptide-Y-like immunoreactivity begins after adrenergic differentiation and ganglionic synaptogenesis in developing bullfrog sympathetic neurons. J Neurosci 10:3305-3312.

Stofer WD, Fatherazi S, Horn JP (1990) Neuropeptide Y mimics a non-adrenergic component of sympathetic vasoconstriction in the bullfrog. J Auton Nerv Syst 31:141-152.

St. Wecker PGR, Farel FB (1989) Neuron number increases in postmetamorphic bullfrogs: dorsal root ganglia. Soc Neurosci Abstr 15: 301.

St. Wecker PGR, Farel PB (1991) Increasing neuron number with body size: a test of the selection hypothesis. Soc Neurosci Abstr 17: 1508

Taylor AC, Kollros JJ (1946) Stages in the normal development of Rana pipiens larvae. Anat Rec 94:7-23.

Tyrrell S, DeJonge JS, Landis SC (1991) Development of neuropeptide expression in rat sympathetic ganglia. Soc Neurosci Abstr 17:746.

von Euler US (1971) Adrenergic neurotransmitter functions. Science 173:202-206.

Wynford-Thomas D, Williams ED (1986) Use of bromodeoxyuridine for cell kinetic studies in intact animals. Cell Tissue Kinet 19:179182. 